\title{
Systems biology from virus to humans
}

\author{
Youri Lee ${ }^{1}$, Yu-Jin Kim ${ }^{1}$, Yu-Jin Jung ${ }^{1}$, Ki-Hye Kim ${ }^{1}$, Young-Man Kwon ${ }^{1}$, Seung $\|$ Kim $^{2}$ and Sang-Moo Kang ${ }^{1 *}$
}

\begin{abstract}
Natural infection and then recovery are considered to be the most effective means for hosts to build protective immunity. Thus, mimicking natural infection of pathogens, many live attenuated vaccines such as influenza virus, and yellow fever vaccine 17D were developed and have been successfully used to induce protective immunity. However, humans fail to generate long-term protective immunity to some pathogens after natural infection such as influenza virus, respiratory syncytial virus (RSV), and human immunodeficiency virus (HIV) even if they survive initial infections. Many vaccines are suboptimal since much mortality is still occurring, which is exampled by influenza and tuberculosis. It is critically important to increase our understanding on protein components of pathogens and vaccines as well as cellular and host responses to infections and vaccinations. Here, we highlight recent advances in gene transcripts and protein analysis results in the systems biology to enhance our understanding of viral pathogens, vaccines, and host cell responses.
\end{abstract}

\section{Review}

\section{Introduction}

Viruses contain all the essential factors necessary for initiating infection and replication in a new target cell. Thus, information on the protein composition of a virus particle often serves as an initial guide in determining functional roles for viral proteins as well as antiviral and/or vaccine antigen target molecules. With advances in proteomics techniques and the availability of annotated genomic sequences for several mammalian species, the view that a virion is a minimal package of its genome and essential viral proteins for the first round of genome replication is being changed. Proteomic analysis of virions identified host proteins that are packaged into the virus particles along with the viral components (Table 1). In particular, enveloped viruses have the capability to incorporate numerous host proteins, both into the interior of the virus particles as well as into the lipid envelope (Cantin et al. 2005; Bortz et al. 2003; Johannsen et al. 2004; Kattenhorn et al. 2004; Zhu et al. 2005). Similarly, host proteins have been detected in vaccinia virions, human immunodeficiency virus (HIV) type 1, and Moloney murine leukemia virus (MoMLV) vector particles (Chung et al. 2006; Chertova et al. 2006; Saphire et al. 2006).

\footnotetext{
* Correspondence: skang24@gsu.edu

${ }^{1}$ Center for Inflammation, Immunity \& Infection, Institute for Biomedical

Sciences, Georgia State University, Atlanta, GA 30303, USA

Full list of author information is available at the end of the article
}

It is expected that cellular proteins found within the virus particles would provide clues as to the virus assembly pathway and events that govern virus infectivity as well as vaccine development.

Vaccination is considered the most effective measure to prevent global infectious diseases. Smallpox and polio diseases are good successful cases of global threats that almost disappeared by effective global vaccination. However, there are still many infectious diseases that claim over 15 million deaths annually. Live attenuated influenza virus (LAIV) vaccine was approved in 2003 and is currently being used for human vaccination. LAIV is safe and effective in young children and adults (Rhorer et al. 2009). Recently, the use of noninfectious viruslike particles (VLPs) that self-assemble by spontaneous interactions of viral structural proteins has been suggested and developed as alternative approaches for developing advanced vaccines for a wide range of viruses that cause disease in humans (Roy and Noad 2009; Kang et al. 2009a; Kang et al. 2009b). It is worth noting that a VLP-based human papillomavirus (HPV) vaccine against HPV responsible for cervical cancer was produced in the yeast system and approved for the market in 2006 (Garland et al. 2007).

Influenza VLPs expressed by recombinant baculovirus (rBV) systems that present multi-component antigens, including HA and matrix 1 (M1), with or without NA, and that are capable of inducing cognate responses against homologous strains of influenza virus have been widely

\section{实}

(c) 2015 Lee et al.; licensee Springer. This is an Open Access article distributed under the terms of the Creative Commons Attribution License (http://creativecommons.org/licenses/by/4.0), which permits unrestricted use, distribution, and reproduction in any medium, provided the original work is properly credited. 
Table 1 Proteomic analysis of representative host cell proteins incorporated into virus or virus-like particles

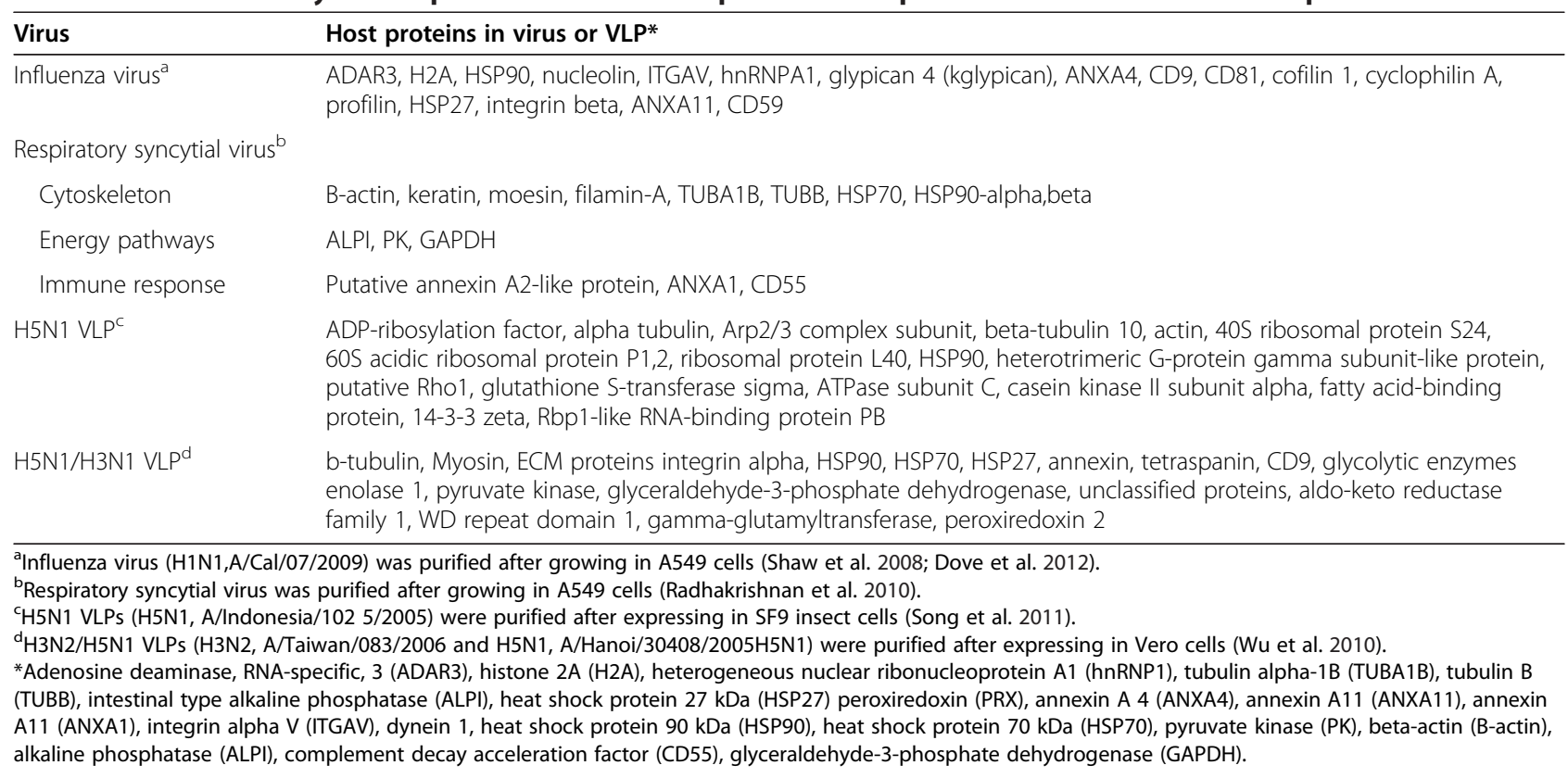

described (Roy and Noad 2009; Kang et al. 2009a; Kang et al. 2009b). In particular, $2009 \mathrm{H} 1 \mathrm{~N} 1$ new pandemic, $\mathrm{H} 5 \mathrm{~N} 1$, and H7N9 avian influenza VLP vaccines were produced by the insect cell rBV expression system, and tested in clinical trials, demonstrating their safety and efficacy (Khurana et al. 2011; Lopez-Macias 2012; Lopez-Macias et al. 2011; Klausberger et al. 2014; Smith et al. 2013; Fries et al. 2013). Also, influenza VLPs were engineered to express highly conserved influenza virus M2 ectodomains and found to induce cross immunity to heterologous influenza virus strains (Kim et al. 2013a; Kim et al. 2014; Kim et al. 2013b).

Any cellular proteins that may be incorporated into viral particles are also likely to be present at very low levels. Mass spectrometry of tryptic peptides combined with database searching for identification is now becoming the preferred and advanced method for such proteomic studies revealing details on protein components even at a very low level (Table 1).

Vaccinology and immunology were born from the pioneering work of scientists such as Jenner and Pasteur over 200 years ago. Despite the common origins of vaccination and immunology concepts, the two disciplines have evolved in parallel directions independently. Immunologists remain largely ignorant about the mechanisms of how vaccines work. Meanwhile, vaccines were made empirically, and until recently, vaccinologists have shown little interest in the immunological mechanisms by which the vaccine confers protective immunity. Better understanding of immunological mechanisms of vaccination is expected to provide informative insights into the rationale design of future vaccines against difficult pathogens.
The innate immune system including dendritic cells (DCs), macrophages, and other immune cells senses viruses, bacteria, parasites, and fungi through pathogenrecognizing receptors (PRRs) (reviewed in (Coffman et al. 2010; Kawai and Akira 2007; Iwasaki and Medzhitov 2010)). The nature of the DC subtypes and the particular PRR triggered plays an essential role in modulating the strength, quality, and memory of adaptive immune responses (Pulendran and Ahmed 2006; Steinman 2008). More than 26,000 genes are estimated to be present in human genomes. Exposure to a pathogen or vaccination introduces changes in the expression of a substantial fraction of these genes. Systems biological tools offer an informative insight into the complex network of the immune system in our body. That is, high-throughput data on the genes, mRNAs, microRNAs, and proteins that constitute the biological networks are providing new information in our overall understanding of complex immune systems. Systems biology capitalizes on several 'omic' technologies that might define and monitor all the components of the systems. Thus, recent advances in the innate immune system and the use of systems biological approaches are providing powerful tools to reveal the basic mechanisms by which the innate immune system modulates protective immune responses to vaccination (Pulendran and Ahmed 2006; Steinman 2008).

This review focuses on proteomic components of some viruses and vaccines (Table 1), cellular responses of host target cells and immune cells upon exposure to virus and vaccines (Table 2), as well as in vivo gene expression profiles in animals and humans in response to respiratory viral infection or certain successful vaccinations. 
Table 2 Representative gene expression profiles in host cells as a result of virus infection or VLP stimulation

\begin{tabular}{lll}
\hline Host cells & Virus/VLPs & Gene expression profiles in host cells* \\
\hline MDCK $^{\text {a }}$ & Influenza & TUBA2, CK-8, B-actin, keratin 10, ANXA1, KCIP-1 \\
VERO $^{b}$ & Influenza & Keratin1, 8, 10, tubulin, TUBA, RBBP4, ITGA3, HSP27, Ndr1, ANXA4, PK, GAPDH, HSP105, ITGAV, dynein 1, \\
& & HSP90, ITGA3, HSP 70 \\
A549 & HRNR, HIST2H2BE, HIST1H2BC, H2AFX, DTX3L, IFI35, SYNE1, SUMO2, MYADM, PARP14, VIM, C21ORF70, \\
& RSV & TFAM, POLDIP3, DEK, EFHD2, KIAA1967, ENO1, ENY2 \\
BEAS-2B ${ }^{\text {dHBEEC }}$ & RTP6VD2, OTOA, SCNN1G, SMA5, CYP4F8, EPB41L4B, ELP2, PRKCE, HBP1, DUSP2, TUBB1, TRNT1, ELOVL5, \\
& RTV & PTPRG, MAP2K7, TSGA10, KRT12, SYN1, SIRPB1
\end{tabular}

MDDC $\quad$ HIV-VLP Expression of genes involved in the morphological and functional changes characterizing the MDDCS activation and maturation: MEF2A, NFE2L2, DC-UbP, PGM3, DGKH, PTGS2, IL8, ARRB1, BTG3, SOSTM1, HLA-DOA - MHC class II, TADA3L, MTHFD2, PRKX, BAG3 KCNK10, member 10, PBEF1

PBMC $^{f} \quad$ HIV-VLP

Expression of genes involved in the morphological and functional changes characterizing the PBMCs activation and maturation: CTSL, IL3RA, SMOX, BCL2, GOS2, IER3, SERPINB2, LIMK2, IL6, IL8, PBFE1, PBX3, IL1-A,B, CCL3 (MIP 1a), CCL7, CCL18, CCL20, CXCL1, CXCL2, CXCL3, CXCL6, CXCL13, INHBA, ACTN1, AQP9, EMR1, SLC25A37, SLCO4A1, MAD, CCL4 (MIP1 $\beta$ )

RAW264.7 $\quad$ HBC-VLP HSP70, Eno1 protein chain A, peroxiredoxin 1, phosphoglycerate kinase, glutathione S-transferase A2, ferritin light chain 1, hypothetical protein, prohibitin, glyceraldehyde-3-phosphate dehydrogenase

\begin{abstract}
${ }^{a}$ Madin-Darby canine kidney (MDCK) cells that were infected with influenza virus (H1N1, A/PR/8/34) (Vester et al. 2010).
${ }^{b}$ Vero (kidney epithelial cells) cells that were infected with influenza virus (H1N1, A/PR/8/34) (Vester et al. 2010).

'A549 (adenocarcinomic human alveolar basal epithelial cells) cells were infected with respiratory syncytial virus (Munday et al. 2010).

dBEAS-2B4 (human bronchial epithelial cell line, subclone S6), human bronchial epithelial cells (HBEC) were infected with respiratory syncytial virus (Huang et al. 2008).

eHuman monocyte-derived dendritic cells (MDDCs) were stimulated with HIV-1 (clade A) Pr55gag virus-like particles (HIV-VLPs) (Arico et al. 2005).

${ }^{\mathrm{f}} \mathrm{CD} 14+$ human peripheral blood mononuclear cells (PBMCs) were stimulated with HIV-1 Pr55gag virus-like particles (HIV-VLPs) (Buonaguro et al. 2008).

${ }^{9}$ RAW264.7 (mouse macrophage cell line) cells were stimulated with hepatitis B virus core protein virus-like particles (HBc-VLPs) (Yang et al. 2008).

*Influenza: H1N1 (A/PR/8/34), HIV-VLp (HIV-1 Pr55gag virus), HBc-VLP (hepatitis B virus). Tubulin alpha (TUBA), protein kinase C inhibitor protein-1 (KCIP-1), nameretinoblastoma binding protein 4 (RBB4), serine/threonine kinase 38 (Ndr), MADS box transcription enhancer factor 2 (MEF2A), nuclear factor-like 2 (NFE2L2), dendritic cell-derived ubiquitin-like protein (DC-UbP), phosphoglucomutase 3 (PGM3), diacylglycerol kinase (DGKH), prostaglandin-endoperoxidase synthase 2 (PTGS2), interleukin 8 (IL-8), arrestin beta 1 (ARRB1), BTG familymember 3 (BTG3), sequestosome 1 (SOSTM1), MHC class II (HLA-DOA), butyrate-induced transcript (HSPC121), transcriptional adaptor 3 (TADA3L), Mst3 and SOK1-related kinase (MST4), UDP-Gal:betaGlcNAc bea 1.4-galactosyltransferase (B4GALT5),

NAD-dependent methylenetetrahydrofolate dehydrogenase (MTHFD2), small glutamine-rich tetratricopeptide repeat (SGTB), protein kinase (PRKX), Nedd4 binding protein 1(X-linked N4BP1), pellino homologue 1(PELI1), sterol-C4-methyl oxidase-like (SC4MOL), BCL2-associated athanogene 3 (BAG3), potassium channel, subfamily K (KCNK10), pre-B-cell colony enhancing factor 1 (PBEF1), hornerin (HRNR), H2B type 2-E (HIST2H2BE), H2B type 1-C/E/F/G/ (HIST1H2BC), H2A (H2AFX), protein deltex-3-like (DTX3L), interferon-induced $35 \mathrm{kDa}$ protein (IFI35), Nesprin-1 (SYNE1), small ubiquitin-related modifier 2 (SUMO2), myeloid-associated differentiation marker (MYADM), poly [ADP-ribose] polymerase 14 (PARP14), vimentin (VIM), uncharacterized protein C21 orf70 (C21ORF70), transcription factor A, mitochondrial (TFAM), polymerase d-interacting protein 3 (POLDIP3), protein DEK (DEK), EF-hand domain-containing protein D2 (EFHD2), protein KIAA1967 (KIAA1967), a-enolase (ENO1), enhancer of yellow 2 transcriptionfactor homologue (ENY2), ATPase, H+ transporting, lysosomal $38 \mathrm{kDa}$, V0 subunit d isoform 2 (ATP6V0D2), otoancorin (OTOA), sodium channel non-voltage-gated 1 gamma (SCNN1G), cytochrome P450 family 4 subfamily F polypeptide 8 (CYP4F8), erythrocyte membrane protein band 4.1 like 4B (EPB41L4B), signal transducer and activator of transcription 3 interacting protein 1(ELP2), protein kinase C epsilon (PRKCE), HMG-box transcription factor 1 downregulated genes (HBP1), dual specificity phosphatase 2 (DUSP2), tubulin beta 1 (TUBB1), tRNA nucleotidyl transferase CCA-adding 1 (TRNT1), ELOVL family member 5 elongation of long chain fatty acids (ELOVL5), protein tyrosine phosphatase receptor type G (PTPRG), mitogenactivated protein kinase 7 (MAP2K7), testis specific 10 (TSGA10), keratin 12 ( KRT12), synapsin I (SYN1), signal-regulatory protein beta 1 (SIRPB1), glucuronidase, beta pseudogene (SMA5), EGF-like module containing, mucin-like, hormone receptor-like sequence 1(EMR1).
\end{abstract}

\section{Cellular and viral proteins within virus and virus-like particles \\ Influenza virus}

With advances in proteomic analysis and studies, a virion is not simply a package of its genome and viral proteins. Numerous host cellular proteins were found to be incorporated into virus particles in particular enveloped virions. HIV virions were found to incorporate Tsg101, cyclophilin A, and APOBEC3G in addition to their viral proteins (Chertova et al. 2006; Saphire et al. 2006; Demirov et al. 2002; Franke et al. 1994; Mariani et al. 2003). Tsg101 host protein was reported to play a crucial role in virus assembly of HIV whereas cyclophilin A modulates HIV-1 infectivity and APOBEC3G is an anti-viral factor that promotes hypermutation of the viral genome (Franke et al. 1994; Mangeat et al. 2003). Among many other cellular proteins, identification of these three host proteins has increased our understanding of how HIV would interact with its host proteins. Nine viral proteins out of the 11 influenza $A$ virus proteins are present in the influenza virion (PB1, PB2, PA, HA, NP, NA, M1, M2, NEP). The glycoproteins hemagglutinin (HA) and neuraminidase (NA) are embedded into the lipid envelope of the influenza virus particle and form the spikes visible under the electron microscope. The ion channel protein M2 is also found within the virion but at a lower level. The matrix M1 protein lies beneath the viral membrane, surrounding the ribonucleoproteins, which consist of eight viral RNA segments coated with the nucleoprotein (NP) and bound by the trimeric polymerase complex (PB1, PB2, PA). The nuclear export protein (NEP) is also found within influenza virus particles.

By utilizing mass spectrometry of tryptic peptides (multidimensional protein identification technology liquid 
chromatography-tandem mass spectrometry (LC-MS/MS) analysis) combined with database searching for identification, 36 host-encoded proteins were identified in the influenza A/WSN/33 (H1N1) virus particles that were grown in Vero (African green monkey kidney) cells (Shaw et al. 2008). The following host cell proteins are also found in other enveloped viruses. (i) Cytoskeletal proteins: Cytoskeletal proteins such as tubulin and actin were present in the interior of influenza virions which most likely reflects their active participation in moving the viral components to the assembly site and possible cytoskeletal reorganization that occurs during bud formation. (ii) Annexins: Several annexin family members (A1, A2, $\mathrm{A} 4$, A5, and A11) were found in influenza virus particles. Annexins are calcium-dependent phospholipidbinding proteins and are proposed to act as scaffolding proteins at certain membrane domains. (iii) Tetraspanins: Two members of the tetraspanin family, CD9 and CD81, were present within influenza virions and are most likely inserted into the viral envelope. Tetraspanins have four transmembrane domains and two extracellular loops and are involved in specialized membrane domains. Tetraspanins (CD9 and CD81) have also been implicated in both fusion and egress pathways for a number of other viruses (Ho et al. 2006; Jolly and Sattentau 2007). (iv) Cyclophilin A: Cyclophilin A (a peptidyl-prolyl isomerase) was shown to be in the core of the influenza virion and in other different viruses. There is a precedent for the involvement of cyclophilin proteins in replication of different viruses. (v) CD59: CD59 is a complement regulatory protein that acts by inhibiting formation of the membrane attack complex. CD59 (glycosylphosphatidylinositol membrane anchored protein) was found to be associated the influenza virus envelope. Enveloped viruses are susceptible to direct complement-mediated lysis and incorporating CD59 (with DAF and CD46) into lipid envelope is considered to play a protective role from membrane attack by the host complement system. This has important implications for virus host-range. The virus produced and transmitted within the same host species would be protected since complement control proteins are highly species specific. However, virus transmitted to another host species would become susceptible to lysis by the complement system from a different host. (vi) Metabolic enzymes: Proteomic analysis of influenza virus particles identified a number of proteins involved in the glycolytic pathway (pyruvate kinase, enolase 1, GAPDH glyceraldehyde-3-phosphate dehydrogenase, phosphoglycerate kinase). It is possible that some of these cellular proteins might have other additional functions such as viral RNA genome transcription.

\section{Respiratory syncytial virus}

Respiratory syncytial virus (RSV) is the most important respiratory virus causing lower respiratory tract infection in young children and neonates. There is no vaccine against RSV. In contrast to influenza virus, formalin inactivated RSV (FI-RSV) in alum adjuvant formulation is known to cause vaccine-enhanced respiratory disease (Kapikian et al. 1969; Kim et al. 1969). Reinfections are common throughout life, indicating that natural RSV infection fails to establish long-lasting immunity (Hall et al. 1991; Piedra 2003; Bont et al. 2002; Nokes et al. 2008; Scott et al. 2006; Glezen et al. 1986). Identification of protein components of RSV might provide a unique clue to therapeutic intervention or vaccine design targets.

The RSV A2 strain was produced in the human respiratory airway cell-line Hep2 and purified using sucrose gradient ultracentrifugation. The RSV protein components were analyzed by one-dimensional nanoLC-MS/MS, resulting in identification of 26 cellular proteins in addition to all the major virus structural proteins (Radhakrishnan et al. 2010). Representative host cell proteins associated with purified RSV particles include proteins associated with the cortical actin network, energy pathways, and heat shock proteins (HSP70, HSC70, and HSP90). In particular, the HSP90 protein was suggested to play an important role in the RSV assembly process. The presence of virus-associated actin network proteins as well as cofilin-1, caveolin-1, and filamin-1 in the mature virus may indicate an important role in RSV assembly in lipid raft microdomains and in maintaining the RSV architecture. Unlike other viruses, high levels of heat-shock proteins associated with RSV particles remain unclear for their significance.

\section{Protein components of VLPs as vaccine candidates}

Influenza VLP vaccines that were produced using the rBV-insect cell expression system were demonstrated to be safe and immunogenic in the clinical trials of healthy adults (Khurana et al. 2011; Lopez-Macias et al. 2011). Insect cell culture derived influenza VLP vaccines were shown to be more immunogenic compared to the conventional egg-substrate split vaccines (a Phase II human clinical trial of the trivalent seasonal influenza VLP vaccine candidate, Novavax, Inc.). These clinical studies demonstrated the safety and efficacy of VLP vaccines produced in insect cells using the rBV expression system. Thus, it is highly significant to have information on protein components of VLP vaccines. Using one-DE-LCMS/MS technology, comprehensive proteomic analysis of the insect cell derived, rBV expressed influenza H5 VLPs identified viral proteins as vaccine target antigens as well as 37 additional host-derived proteins (Song et al. 2011). Many of host-cell-derived proteins in influenza VLPs are known to be present in other enveloped viruses and involved in different cellular structures and functions including those from the cytoskeleton, translation, chaperone, and metabolism. Influenza H5 VLPs produced 
in insect cells were found to be associated with host proteins involved in actin cytoskeleton, vesicular trafficking (ADP-ribosylation factor, vesicle-associated membrane proteins, vacuolar protein sorting 28 , myosin II essential light chain), heat-shock protein 90, ribosomal proteins, putative ubiquitin/ ribosomal protein S27Ae fusion protein, and cell-signaling-related proteins (heterotrimeric guanine nucleotide binding protein gamma subunit-like protein, Rho1). As expected, many rBV vectorderived proteins were also found to be in H5 VLPs. These structural proteins originated from rBV include occlusion derived and polyhedron associated proteins (AcOrf$102,-114)$, capsid or capsid associated proteins, and baculovirus envelope proteins.

Mammalian influenza VLPs may more closely mimic authentic virions in their morphology, in functional HA, and in other molecular constituents. Stably transformed Vero cells expressing influenza M1, M2, HA, and NA were used to produce mammalian influenza H3N2 VLPs and H5N1 VLPs (Song et al. 2011). Proteomic analysis of mammalian VLPs using LC-MS/MS technologies identified 22 VLP-associated cellular proteins that are analogous to those cellular proteins commonly found in the influenza virions (Song et al. 2011). These cellular proteins incorporated into mammalian influenza VLPs include cytoskeleton proteins, extracellular matrix proteins, heat shock proteins, annexins, tetraspanins, clathrin heavy chain, and glycolytic enzymes. Thus, the cellular proteins identified in VLPs without viral genomes are important in the normal virus life cycle during virus assembly and budding from the host cells.

\section{Host cell gene expression profiles upon viral infections or in response to VLPs}

A proteomic approach applying the quantitative 2-D DIGE and nanoHPLC-nanoESI-MS/MS analysis was used to investigate the dynamic cellular host cell response induced by influenza virus infection in two different cell lines, Madin-Darby canine kidney (MDCK) and Vero cells. Upon influenza virus (A/PR/8/34) infection, changes in gene expression of MDCK infected cells were observed in the interferon (IFN)-induced signal transduction, cytoskeleton remodeling, vesicle transport, and proteolysis (Vester et al. 2010). In Vero cells infected with influenza virus, alterations of gene expression include heat shock and oxidative stress response-related proteins.

To gain an understanding of the RSV associated host cell gene expression, differentially expressed genes in human respiratory epithelial cells (A549) were determined by cDNA microarray analysis after RSV infection (Martinez et al. 2007). Among 85 genes that were up-regulated at early times post infection ( 0 to $6 \mathrm{~h}$ post infection (pi)), most highly expressed genes are involved in chemotaxis, inflammation, and some integrins. Genes related to IFN- stimulation and NF-kB pathways were up-regulated between 6 and $12 \mathrm{~h}$ pi. At later times post infection, immune response-related genes were expressed at high levels. These findings suggest a temporal relationship between RSV infection and the host response to RSV replication. Supplementary validation experiments using conventional methods are required to confirm these findings.

HIV-1 gag virus-like particles (HIV-VLPs) produced by the recombinant baculovirus expression system was used to stimulate $\mathrm{CD} 14^{+}$monocyte-derived dendritic cells (MDDCs) enriched from peripheral blood mononuclear cells (PBMCs) of normal healthy donors (Buonaguro et al. 2008). Genomic transcriptional profile of HIV-VLPs activated MDDCs revealed high expression of genes that are responsible for activation and maturation of MDDCs. Representative genes up-regulated include antigen processing and presentation (IL3RA, BCL2), cell shape and extracellular matrix, chemokine and cytokines (IL-6), cytokine network (IL1A, B), cytokine-receptor interactions, immune response membrane proteins, chemokine receptors (CCL3, 4), and Toll-like receptor (TLR) signaling pathway (IL8). Similar data of gene expression profile were also reported to be observed using PBMCs activated by HIV-VLPs (Buonaguro et al. 2008). The same group of study demonstrated that the effects of HIV-VLPs on MDDCs are not mediated through TLR2 and TLR4 signaling (Buonaguro et al. 2006). Also, influenza VLPloaded MDDCs that were obtained from human healthy donors were demonstrated to be effective in generating functional CD8 $\mathrm{T}$ cells (Song et al. 2010), implicating that VLP vaccines can induce both humoral and cellular host immune responses.

Hepatitis B virus core antigen VLP (HBc-VLP)-pulsed and control macrophage cells (RAW264.7) were subjected to two-dimensional electrophoresis and tandem MS (Yang et al. 2008). Analysis of differentially expressed proteins revealed that heat-shock protein 70 and prohibitin in addition to proteins in the glycolytic pathway were highly up-regulated upon stimulation with HBc-VLPs. It is speculated that stress-response proteins (HSP70, prohibitin) may contribute to the uptake, processing, and presentation of VLP vaccine particles.

\section{Animal models and systems biology to better understand pathogenesis and vaccination}

The dynamics of virus pathogenesis are multifaceted and can be better comprehended by looking at the system as a whole. Human patients with highly pathogenic avian influenza $\mathrm{H} 5 \mathrm{~N} 1$ virus typically develop a viral primary pneumonia progressing rapidly to acute respiratory distress syndrome (Abdel-Ghafar et al. 2008). An aberrant immune response is thought to play a significant role in the severe respiratory disease that may ultimately lead to death (Peiris et al. 2009). The term 'cytokine storm' 
referring to an uncontrolled inflammatory response is often associated with $\mathrm{H} 5 \mathrm{~N} 1$ virus pathogenesis (Tisoncik et al. 2012). Human patients infected with H5N1 virus were shown to have high serum levels of pro- and antiinflammatory cytokines (IL-6, IL-10, IFN- $\gamma$ ), macrophage and neutrophil chemoattractant chemokines (CxCL10, CXCL2, IL-8) (de Jong et al. 2006; Peiris et al. 2004; To et al. 2001). Host response to influenza H5N1 virus has been investigated in non-human primate, mouse, and ferret models. Global transcriptional profiling of infected lungs has revealed that virulence of influenza virus is associated with increased early and sustained inflammatory responses. Genes that showed correlates with disease severity during $\mathrm{H} 5 \mathrm{~N} 1$ virus infection include inflammasome components, viral sensing, neutrophil activation, NF-KB signaling, and chemokine signaling (Ibricevic et al. 2006; Cilloniz et al. 2010; Baskin et al. 2009; Cameron et al. 2008; Chang et al. 2011; Shinya et al. 2012).

It is suggested that lung homeostasis is lost when the innate immune system reached a high level of activation but was unable to contain the pathogen before viral cytopathicity (Boon et al. 2011; Sanders et al. 2011). The depletion of innate immune cell types lowered inflammatory cytokine levels in mouse lung homogenates but resulted in elevated lung viral titers, systemic virus spread, and reduced survival (Tumpey et al. 2005). Mice with decreased myeloid infiltrates and lack of NLRP3 inflammasome activation exhibited high susceptibility to influenza infection (Allen et al. 2009; Thomas et al. 2009). Selective neutrophil targeting in infected mice caused enhanced mortality (Tate et al. 2009). Therefore, innate inflammatory cells have host-beneficial functions rather than a primary causal role in pathology (Brincks et al. 2008; Tate et al. 2012).

An alternative view is that lung function is largely dysregulated through the damaging effects of leukocytes on epithelial and endothelial cells (Aldridge et al. 2009; Le Goffic et al. 2006; Lin et al. 2008). In support for this idea, monocyte-derived inflammatory macrophages and dendritic cells contributed to fatality (Lin et al. 2008). The relative pathogenic contributions of direct viral cytopathic damage versus dysregulated host inflammatory responses to lethal influenza infections remain as an important question to be answered. By using extensive microarray analysis of multigene transcriptional signatures from infected mouse lungs, a recent study suggested that differential activation of inflammatory signaling networks distinguished lethal from sublethal infections. From combined flow cytometry and gene expression analysis of isolated cell subpopulations from infected mouse lungs showed that neutrophil influx was largely responsible for the predictive transcriptional signatures. Together with these gene expression and flow data, automated imaging analysis identified chemokine-driven proinflammatory neutrophils, which might be activated by lethal viral loads. In line with these data, attenuation, but not ablation, of the neutrophil-driven response was shown to improve survival without changing viral spread. These findings with a possible a roadmap for the systematic dissection of infectionassociated tissues support evidence for the primary contribution of damaging innate inflammation to some forms of influenza-induced lethality and provide. To more clearly differentiate host protective from damaging immunity, comprehensive data sets at both the organ and the cell level are needed.

As described above, RSV is also an important human respiratory pathogen against which there is no vaccine. Systemic gene expression signatures have been examined in lungs of mice infected with RSV (Pennings et al. 2011; Janssen et al. 2007; Tripp et al. 2013). A robust transcriptional response of interferon-associated and innate immunity genes was observed at day 1 (pi) but was reduced by day $3 \mathrm{pi}$, and the peak lung transcriptional response preceded the peak of viral replication. Host genes that were expressed were diverse and involved in the IFN response, inflammation, chemoattraction, and antigen processing. In particular, cytokine genes such as IL-1 $\beta$ orchestrate the proinflammatory response while others including intracellular reactive oxygen species (ROS) were effectors of inflammation (Janssen et al. 2007; Tripp et al. 2013; Segovia et al. 2012).

Host innate immune responses in response to vaccination are relatively not well understood yet. The live attenuated yellow fever vaccine 17D (YF-17D) is considered one of most effective vaccine with a 65-year history. YF17D was shown to activate human monocyte-derived DCs by up-regulating CD80, CD86 markers and inflammatory cytokines (IL-6, TNF- $\alpha$ ), and chemokines (IP-10, MCP-1) (Querec et al. 2006). Using CD11 ${ }^{+}$DCs derived from mutant mice, YF-17D was found to stimulate DCs via multiple TLRs $2,7,8$, and 9 to elicit the proinflammatory cytokines IL-12p40, IL-6, and IFN- $\alpha$. Mice with a transfer of OT-I T cell receptor transgenic $\mathrm{T}$ cells and inoculated with YF-Ova8 induced a mixed $\mathrm{T}$ helper cell (Th)1/Th2 cytokine profile and CD8 T cells. Thus, effective vaccines may need to activate multiple innate immune components.

\section{Systems biology in humans for better understanding of disease and vaccination} Systems biology in humans with respiratory viral infections

Systems biology is a newly advancing field that uses an interdisciplinary approach aimed at understanding and predicting the properties of a living system through systematic quantification of all its components and intensive mathematical and computational modeling. Each component of the system is measured using high-throughput 'omic' techniques and in theory examined from the cellular level 
to the whole organism. Systems technologies include transcriptomic (microarray gene expression), modern mass spectrometry (proteomics, lipidomics, metabolomics), genomics, and protein-DNA interaction (chromatin immunoprecipitation).

A recent study (Mejias et al. 2013) reported whole blood gene expression profiles of microarray data to assess disease severity in infants (ages $<6$ months, 2 to 24 months) with respiratory syncytial virus infection in comparison with influenza and human rhinovirus (HRV), attempting to identify biomarkers that can objectively predict RSV disease severity. Despite the fact that influenza, RSV, and HRV infect common respiratory tracts, this study demonstrated that the degree of activation/ suppression of specific immune-related genes was markedly different. Influenza stimulated a stronger activation of interferon, inflammation, monocyte, and innate immune response genes compared with RSV and rhinovirus. Neutrophil-related genes were significantly overexpressed in patients with RSV, followed by patients with rhinovirus, and were at a lower level in patients with influenza. Interestingly, RSV was associated with marked suppression of genes involved in B cell, T cell, lymphoid lineage, and antimicrobial responses. In contrast, this suppression was significantly milder or absent in children with influenza and rhinovirus.

The overexpression of interferon and innate immunity genes was similar in children with moderate and severe RSV but greater than that in children with mild RSV disease. The overexpression of neutrophil, monocyte, and innate immunity genes induced during the RSV acute disease faded over time. However, $\mathrm{T}$ cell lymphoid lineage and antimicrobial response genes were suppressed during the acute phase and then recovered back to normal levels. Remarkably, the suppression of B cell genes was persistent when patients' samples were analyzed 1 month after the acute infection. This low level of B cell genes might explain partially the less protective antibody responses after acute RSV infection. This study also indicates that RSV suppressed both the adaptive and innate responses more severely in younger infants less than 6 months old. Children with severe RSV demonstrated significantly greater underexpression of genes associated with $\mathrm{T}$ cells, cytotoxic and NK cells, and plasma cells.

Influenza triggers a more robust immune response than RSV, with greater induction of respiratory and systemic cytokines (Garofalo et al. 2005; Gill et al. 2008; Welliver et al. 2007). Antiviral responses against influenza and RSV were shown to be correlated with the interferon signature gene expression from peripheral blood mononuclear cells isolated from patients with acute influenza or RSV bronchiolitis (Ioannidis et al. 2012). This study provides evidence of the profound systemic dysregulation of both the innate and adaptive immune response induced by RSV infection in children and supports systems biology of gene expression profiling as a practical and powerful strategy to objectively stratify children with viral infection such as RSV. Nonetheless, these observations will require further analysis, as they may have implications for RSV vaccine development.

\section{Systems vaccinology}

One potential application of systems biology is to predict vaccine efficacy in humans. Molecular patterns or signatures of genes in the blood after vaccination might predict the later development of protective immune responses, representing a strategy to prospectively determine vaccine efficacy. Blood cells provide a snap-shot of many lineages and differentiation states within the immune system including the sites of vaccination. Microarray analyses using the Affymetrix Human Genome U133 Plus 2.0 array of total PBMCs revealed a molecular signature comprised of genes that are involved in innate sensing of viruses and antiviral immunity, in most of the vaccines.

YF-17D is a live-attenuated yellow fever virus, one of most effective successful human vaccines ever developed (Querec et al. 2009; Gaucher et al. 2008) and would provide an excellent model for systems vaccinology study in humans. YF-17D single vaccination induces antigenspecific $\mathrm{CD}^{+} \mathrm{T}$ cells and neutralizing antibody responses in humans that persist for several decades (Pulendran 2009; Pulendran et al. 2013). Recent studies (Querec et al. 2009; Gaucher et al. 2008) reported transcriptomic analysis of PBMCs isolated 3 to 7 day-post-vaccination of healthy adults with YF-17D. In these studies, a pattern of gene expression profile was revealed, which consists of genes encoding proteins involved in antiviral sensing and viral immunity, including the type I IFN pathway. It seems to be that the YF-17D vaccine is mimicking an acute viral infection.

Using computational analysis, signatures of gene expression in human PBMCs after vaccination appeared to be correlated with the magnitude of the antigenspecific $\mathrm{CD} 8^{+} \mathrm{T}$ cell and neutralizing antibody responses afterward (Querec et al. 2009). The functional relevance of one of the genes within the predictive signatures was speculated from machine-learning techniques to validate the predictive capacity (ref 22). Eukaryotic initiation factor- $\alpha$ kinase 4 (EIF2AK4) would be involved in programming professional antigen presenting cells (DCs) to stimulate $\mathrm{CD} 8^{+} \mathrm{T}$ cell responses (Querec et al. 2009). A TNFRSF17 gene signature was predicted to be correlated with neutralizing antibody responses. TNFRSF17 encodes the receptor for the B-cell growth factor BLyS-BAFF known to play a key role in the differentiation of plasma cells (Vincent et al. 2013). 
The potential application of systems vaccinology in humans was further extended by studies on immunity to human influenza vaccines, the trivalent inactivated seasonal influenza vaccine (TIV) (Nakaya et al. 2011; Bucasas et al. 2011; Franco et al. 2013), and LAIV (FluMist) (Nakaya et al. 2011). TIV is the most common flu shot vaccine, which is a mixture of inactivated split $\mathrm{H} 1 \mathrm{~N} 1$, H3N2, and influenza B vaccines. To determine whether molecular signatures after YF-17D vaccination would be similar to other vaccines such as influenza, a recent study carried out a systems analysis of responses to TIV and LAIV in young healthy adults during three consecutive influenza seasons (Nakaya et al. 2011). The group of people who received TIV showed higher antibody titers and more plasmablasts compared to the group who received nasal spray of LAIV. As expected from the fact that replicating LAIV infects mucosal tissues of respiratory tracts, humans with a nasal spray of LAIV showed a robust type I IFN antiviral transcriptomic signatures. TIV-vaccinated humans also expressed some gene encoding type I interferons and related proteins as well as gene encoding proinflammatory mediators (Nakaya et al. 2011). In this study, genes that are involved in innate sensing of viruses and antiviral responses were highly expressed within 1 to 3 days after vaccination of humans (Nakaya et al. 2011). After 3 to 7 days of vaccination, the up-regulated genes (TNRSF17, XBP-1) were found to be involved in the differentiation of plasmablasts, which is likely to be correlated with the magnitude of the later hemagglutin titers (Nakaya et al. 2011). Other studies also demonstrated a plausible correlation between this 'plasmablast signature' and its capacity to predict antibody titers (Obermoser et al. 2013; Furman et al. 2013; Tsang et al. 2014).

\section{Conclusions}

In summary, recent advances in applying systems-level approaches to virus, vaccines, cells, organs, animals, and even to humans revealed extensive new information on gene expression and protein components, thus showing some promises in future. This new information extend our understanding in the pathogen-host cell interactions, host cellular responses, disease pathogenesis, host immune responses, and eventually new therapeutics and novel vaccine development. However, it should be reminded that microarray data may fail to provide convincing significance in our complex biological systems. In addition, the results of systems analysis need to be validated by experiments generating functional data such as protein techniques, gene perturbation, or deficient animal models. Finally, systems biology requires multidisciplinary and close collaborative experts including biologists, vaccinologists, immunologists, systems bioinformatics, computational specialists, and clinicians.

\section{Authors' contributions}

YL, YJK, YJJ, KHK, YMK, and SMK carried out collecting all information and arranging the Tables. SIK has collected the proteomic data. YL has contributed to drafting the manuscript and arranging the references. SMK finalized writing the manuscript with complete references. All authors read and approved the final manuscript.

\section{Competing interests}

The authors declare that they have no competing interests.

\section{Acknowledgements}

This work was partially supported by NIH/NIAID grants Al105170 (S.M.K.) and Al093772 (S.M.K.).

\section{Author details}

${ }^{1}$ Center for Inflammation, Immunity \& Infection, Institute for Biomedical Sciences, Georgia State University, Atlanta, GA 30303, USA. Division of Life Science, Korea Basic Science Institute, Daejeon 305-333, South Korea.

Received: 8 January 2015 Accepted: 15 January 2015

Published online: 05 February 2015

\section{References}

Abdel-Ghafar AN, Chotpitayasunondh T, Gao Z, Hayden FG, Nguyen DH, de Jong MD, Naghdaliyev A, Peiris JS, Shindo N, Soeroso S, Uyeki TM (2008) Update on avian influenza $A$ (H5N1) virus infection in humans. N Engl J Med 358:261-273

Aldridge JR Jr, Moseley CE, Boltz DA, Negovetich NJ, Reynolds C, Franks J, Brown SA, Doherty PC, Webster RG, Thomas PG (2009) TNF/iNOS-producing dendritic cells are the necessary evil of lethal influenza virus infection. Proc Natl Acad Sci U S A 106:5306-5311

Allen IC, Scull MA, Moore CB, Holl EK, McElvania-TeKippe E, Taxman DJ, Guthrie EH, Pickles RJ, Ting JP (2009) The NLRP3 inflammasome mediates in vivo innate immunity to influenza A virus through recognition of viral RNA. Immunity 30:556-565

Arico E, Wang E, Tornesello ML, Tagliamonte M, Lewis GK, Marincola FM, Buonaguro FM, Buonaguro L (2005) Immature monocyte derived dendritic cells gene expression profile in response to virus-like particles stimulation. J Transl Med 3:45

Baskin CR, Bielefeldt-Ohmann H, Tumpey TM, Sabourin PJ, Long JP, Garcia-Sastre A, Tolnay AE, Albrecht R, Pyles JA, Olson PH, Aicher LD, Rosenzweig ER, Murali-Krishna K, Clark EA, Kotur MS, Fornek JL, Proll S, Palermo RE, Sabourin CL, Katze MG (2009) Early and sustained innate immune response defines pathology and death in nonhuman primates infected by highly pathogenic influenza virus. Proc Natl Acad Sci U S A 106:3455-3460

Bont L, Versteegh J, Swelsen WT, Heijnen CJ, Kavelaars A, Brus F, Draaisma JM, Pekelharing-Berghuis M, van Diemen-Steenvoorde RA, Kimpen JL (2002) Natural reinfection with respiratory syncytial virus does not boost virusspecific T-cell immunity. Pediatr Res 52:363-367

Boon AC, Finkelstein D, Zheng M, Liao G, Allard J, Klumpp K, Webster R, Peltz G, and Webby RJ (2011) H5N1 influenza virus pathogenesis in genetically diverse mice is mediated at the level of viral load. mBio 2(5).

Bortz E, Whitelegge JP, Jia Q, Zhou ZH, Stewart JP, Wu TT, Sun R (2003) Identification of proteins associated with murine gammaherpesvirus 68 virions. J Virol 77:13425-13432

Brincks EL, Katewa A, Kucaba TA, Griffith TS, Legge KL (2008) CD8 T cells utilize TRAIL to control influenza virus infection. J Immunol 181:4918-4925

Bucasas KL, Franco LM, Shaw CA, Bray MS, Wells JM, Nino D, Arden N, Quarles JM, Couch RB, Belmont JW (2011) Early patterns of gene expression correlate with the humoral immune response to influenza vaccination in humans. $J$ Infect Dis 203:921-929

Buonaguro L, Tornesello ML, Tagliamonte M, Gallo RC, Wang LX, Kamin-Lewis R, Abdelwahab S, Lewis GK, Buonaguro FM (2006) Baculovirus-derived human immunodeficiency virus type 1 virus-like particles activate dendritic cells and induce ex vivo T-cell responses. J Virol 80:9134-9143

Buonaguro L, Monaco A, Arico E, Wang E, Tornesello ML, Lewis GK, Marincola FM, Buonaguro FM (2008) Gene expression profile of peripheral blood mononuclear cells in response to HIV-VLPs stimulation. BMC Bioinformatics 9(Suppl 2):S5

Cameron CM, Cameron MJ, Bermejo-Martin JF, Ran L, Xu L, Turner PV, Ran R, Danesh A, Fang Y, Chan PK, Mytle N, Sullivan TJ, Collins TL, Johnson MG, Medina JC, Rowe T, Kelvin DJ (2008) Gene expression analysis of host innate immune responses during Lethal H5N1 infection in ferrets. J Virol 82:11308-11317 
Cantin R, Methot S, Tremblay MJ (2005) Plunder and stowaways: incorporation of cellular proteins by enveloped viruses. J Virol 79:6577-6587

Chang ST, Tchitchek N, Ghosh D, Benecke A, Katze MG (2011) A chemokine gene expression signature derived from meta-analysis predicts the pathogenicity of viral respiratory infections. BMC Syst Biol 5:202

Chertova E, Chertov O, Coren LV, Roser JD, Trubey CM, Bess JW Jr, Sowder RC 2nd, Barsov E, Hood BL, Fisher RJ, Nagashima K, Conrads TP, Veenstra TD, Lifson JD, Ott DE (2006) Proteomic and biochemical analysis of purified human immunodeficiency virus type 1 produced from infected monocytederived macrophages. J Virol 80:9039-9052

Chung CS, Chen CH, Ho MY, Huang CY, Liao CL, Chang W (2006) Vaccinia virus proteome: identification of proteins in vaccinia virus intracellular mature virion particles. J Virol 80:2127-2140

Cilloniz C, Pantin-Jackwood MJ, Ni C, Goodman AG, Peng X, Proll SC, Carter VS, Rosenzweig ER, Szretter KJ, Katz JM, Korth MJ, Swayne DE, Tumpey TM, Katze MG (2010) Lethal dissemination of H5N1 influenza virus is associated with dysregulation of inflammation and lipoxin signaling in a mouse model of infection. J Virol 84:7613-7624

Coffman RL, Sher A, Seder RA (2010) Vaccine adjuvants: putting innate immunity to work. Immunity 33:492-503

De-Jong MD, Simmons CP, Thanh TT, Hien VM, Smith GJ, Chau TN, Hoang DM, Chau NV, Khanh TH, Dong VC, Qui PT, Cam BV, Ha-do Q, Guan Y, Peiris JS, Chinh NT, Hien TT, Farrar J (2006) Fatal outcome of human influenza A (H5N1) is associated with high viral load and hypercytokinemia. Nat Med 12:1203-1207

Demirov DG, Ono A, Orenstein JM, Freed EO (2002) Overexpression of the $\mathrm{N}$-terminal domain of TSG101 inhibits HIV-1 budding by blocking late domain function. Proc Natl Acad Sci U S A 99:955-960

Dove BK, Surtees R, Bean TJ, Munday D, Wise HM, Digard P, Carroll MW, Ajuh P, Barr JN, Hiscox JA (2012) A quantitative proteomic analysis of lung epithelial (A549) cells infected with 2009 pandemic influenza A virus using stable isotope labelling with amino acids in cell culture. Proteomics 12:1431-1436

Franco LM, Bucasas KL, Wells JM, Nino D, Wang X, Zapata GE, Arden N, Renwick A, Yu P, Quarles JM, Bray MS, Couch RB, Belmont JW, Shaw CA (2013) Integrative genomic analysis of the human immune response to influenza vaccination. elife 2:e00299

Franke EK, Yuan HE, Luban J (1994) Specific incorporation of cyclophilin A into HIV-1 virions. Nature 372:359-362

Fries LF, Smith GE, Glenn GM (2013) A recombinant viruslike particle influenza A (H7N9) vaccine. N Engl J Med 369:2564-2566

Furman D, Jojic V, Kidd B, Shen-Orr S, Price J, Jarrell J, Tse T, Huang H, Lund P, Maecker HT, Utz PJ, Dekker CL, Koller D, Davis MM (2013) Apoptosis and other immune biomarkers predict influenza vaccine responsiveness. Mol Syst Biol 9:659

Garland SM, Hernandez-Avila M, Wheeler CM, Perez G, Harper DM, Leodolter S, Tang GW, Ferris DG, Steben M, Bryan J, Taddeo FJ, Railkar R, Esser MT, Sings HL, Nelson M, Boslego J, Sattler C, Barr E, Koutsky LA (2007) Quadrivalent vaccine against human papillomavirus to prevent anogenital diseases. N Engl J Med 356:1928-1943

Garofalo RP, Hintz KH, Hill V, Patti J, Ogra PL, Welliver RC Sr (2005) A comparison of epidemiologic and immunologic features of bronchiolitis caused by influenza virus and respiratory syncytial virus. J Med Virol 75:282-289

Gaucher D, Therrien R, Kettaf N, Angermann BR, Boucher G, Filali-Mouhim A, Moser JM, Mehta RS, Drake DR 3rd, Castro E, Akondy R, Rinfret A, YassineDiab B, Said EA, Chouikh Y, Cameron MJ, Clum R, Kelvin D, Somogyi R, Greller LD, Balderas RS, Wilkinson P, Pantaleo G, Tartaglia J, Haddad EK, Sekaly RP (2008) Yellow fever vaccine induces integrated multilineage and polyfunctional immune responses. J Exp Med 205:3119-3131

Gill MA, Long K, Kwon T, Muniz L, Mejias A, Connolly J, Roy L, Banchereau J, Ramilo O (2008) Differential recruitment of dendritic cells and monocytes to respiratory mucosal sites in children with influenza virus or respiratory syncytial virus infection. J Infect Dis 198:1667-1676

Glezen WP, Taber LH, Frank AL, Kasel JA (1986) Risk of primary infection and reinfection with respiratory syncytial virus. Am J Dis Child 140:543-546

Hall CB, Walsh EE, Long CE, Schnabel KC (1991) Immunity to and frequency of reinfection with respiratory syncytial virus. J Infect Dis 163:693-698

Ho SH, Martin F, Higginbottom A, Partridge LJ, Parthasarathy V, Moseley GW, Lopez P, Cheng-Mayer C, Monk PN (2006) Recombinant extracellular domains of tetraspanin proteins are potent inhibitors of the infection of macrophages by human immunodeficiency virus type 1. J Virol 80:6487-6496
Huang YC, Li Z, Hyseni X, Schmitt M, Devlin RB, Karoly ED, Soukup JM (2008) Identification of gene biomarkers for respiratory syncytial virus infection in a bronchial epithelial cell line. Genomic Med 2:113-125

Ibricevic A, Pekosz A, Walter MJ, Newby C, Battaile JT, Brown EG, Holtzman MJ, Brody SL (2006) Influenza virus receptor specificity and cell tropism in mouse and human airway epithelial cells. J Virol 80:7469-7480

loannidis I, McNally B, Willette M, Peeples ME, Chaussabel D, Durbin JE, Ramilo O, Mejias A, Flano E (2012) Plasticity and virus specificity of the airway epithelial cell immune response during respiratory virus infection. J Virol 86:5422-5436

Iwasaki A, Medzhitov R (2010) Regulation of adaptive immunity by the innate immune system. Science 327:291-295

Janssen R, Pennings J, Hodemaekers H, Buisman A, van Oosten M, de Rond L, Ozturk K, Dormans J, Kimman T, Hoebee B (2007) Host transcription profiles upon primary respiratory syncytial virus infection. J Virol 81:5958-5967

Johannsen E, Luftig M, Chase MR, Weicksel S, Cahir-McFarland E, Illanes D, Sarracino D, Kieff E (2004) Proteins of purified Epstein-Barr virus. Proc Natl Acad Sci U S A 101:16286-16291

Jolly C, Sattentau QJ (2007) Human immunodeficiency virus type 1 assembly, budding, and cell-cell spread in T cells take place in tetraspanin-enriched plasma membrane domains. J Virol 81:7873-7884

Kang SM, Pushko P, Bright RA, Smith G, Compans RW (2009a) Influenza virus-like particles as pandemic vaccines. Curr Top Microbiol Immunol 333:269-289

Kang SM, Song JM, Quan FS, Compans RW (2009b) Influenza vaccines based on virus-like particles. Virus Res 143:140-146

Kapikian AZ, Mitchell RH, Chanock RM, Shvedoff RA, Stewart CE (1969) An epidemiologic study of altered clinical reactivity to respiratory syncytial (RS) virus infection in children previously vaccinated with an inactivated RS virus vaccine. Am J Epidemiol 89:405-421

Kattenhorn LM, Mills R, Wagner M, Lomsadze A, Makeev V, Borodovsky M, Ploegh HL, Kessler BM (2004) Identification of proteins associated with murine cytomegalovirus virions. J Virol 78:11187-11197

Kawai T, Akira S (2007) TLR signaling. Semin Immunol 19:24-32

Khurana S, Wu J, Verma N, Verma S, Raghunandan R, Manischewitz J, King LR, Kpamegan E, Pincus S, Smith G, Glenn G, Golding H (2011) H5N1 virus-like particle vaccine elicits cross-reactive neutralizing antibodies that preferentially bind to the oligomeric form of influenza virus hemagglutinin in humans. J Virol 85:10945-10954

Kim HW, Canchola JG, Brandt CD, Pyles G, Chanock RM, Jensen K, Parrott RH (1969) Respiratory syncytial virus disease in infants despite prior administration of antigenic inactivated vaccine. Am J Epidemiol 89:422-434

Kim MC, Lee JS, Kwon YM, Eunju O, Lee YJ, Choi JG, Wang BZ, Compans RW, Kang SM (2013a) Multiple heterologous M2 extracellular domains presented on virus-like particles confer broader and stronger M2 immunity than live influenza A virus infection. Antivir Res 99:328-335

Kim MC, Song JM, Eunju O, Kwon YM, Lee YJ, Compans RW, Kang SM (2013b) Virus-like particles containing multiple M2 extracellular domains confer improved cross-protection against various subtypes of influenza virus. Mol Ther 21:485-492

Kim MC, Lee YN, Hwang HS, Lee YT, Ko EJ, Jung YJ, Cho MK, Kim YJ, Lee JS, Ha SH, Kang SM (2014) Influenza M2 virus-like particles confer a broader range of cross protection to the strain-specific pre-existing immunity. Vaccine 32:5824-5831

Klausberger M, Wilde M, Palmberger D, Hai R, Albrecht RA, Margine I, Hirsh A, Garcia-Sastre A, Grabherr R, Krammer F (2014) One-shot vaccination with an insect cell-derived low-dose influenza A H7 virus-like particle preparation protects mice against H7N9 challenge. Vaccine 32:355-362

Le Goffic R, Balloy V, Lagranderie M, Alexopoulou L, Escriou N, Flavell R, Chignard M, Si-Tahar M (2006) Detrimental contribution of the Toll-like receptor (TLR)3 to influenza A virus-induced acute pneumonia. PLoS Pathog 2:e53

Lin KL, Suzuki Y, Nakano H, Ramsburg E, Gunn MD (2008) CCR2+ monocytederived dendritic cells and exudate macrophages produce influenza-induced pulmonary immune pathology and mortality. J Immunol 180:2562-2572

Lopez-Macias, C (2012) Virus-like particle (VLP)-based vaccines for pandemic influenza: Performance of a VLP vaccine during the 2009 influenza pandemic. Human Vaccines Immunotherapeutics 8(3):411-414.

Lopez-Macias C, Ferat-Osorio E, Tenorio-Calvo A, Isibasi A, Talavera J, Arteaga-Ruiz O, Arriaga-Pizano L, Hickman SP, Allende M, Lenhard K, Pincus S, Connolly K, Raghunandan R, Smith G, Glenn G (2011) Safety and immunogenicity of a virus-like particle pandemic influenza A (H1N1) 2009 vaccine in a blinded, randomized, placebo-controlled trial of adults in Mexico. Vaccine 29:7826-7834 
Mangeat B, Turelli P, Caron G, Friedli M, Perrin L, Trono D (2003) Broad antiretroviral defence by human APOBEC3G through lethal editing of nascent reverse transcripts. Nature 424:99-103

Mariani R, Chen D, Schrofelbauer B, Navarro F, Konig R, Bollman B, Munk C, Nymark-McMahon H, Landau NR (2003) Species-specific exclusion of APOBEC3G from HIV-1 virions by Vif. Cell 114:21-31

Martinez I, Lombardia L, Garcia-Barreno B, Dominguez O, Melero JA (2007) Distinct gene subsets are induced at different time points after human respiratory syncytial virus infection of A549 cells. J Gen Virol 88:570-581

Mejias A, Dimo B, Suarez NM, Garcia C, Suarez-Arrabal MC, Jartti T, Blankenship D, Jordan-Villegas A, Ardura MI, Xu Z, Banchereau J, Chaussabel D, Ramilo O (2013) Whole blood gene expression profiles to assess pathogenesis and disease severity in infants with respiratory syncytial virus infection. PLoS Med 10:e1001549

Munday DC, Emmott E, Surtees R, Lardeau CH, Wu W, Duprex WP, Dove BK, Barr JN, Hiscox JA (2010) Quantitative proteomic analysis of A549 cells infected with human respiratory syncytial virus. Mol Cell Proteomics 9:2438-2459

Nakaya HI, Wrammert J, Lee EK, Racioppi L, Marie-Kunze S, Haining WN, Means AR, Kasturi SP, Khan N, Li GM, McCausland M, Kanchan V, Kokko KE, Li S, Elbein R, Mehta AK, Aderem A, Subbarao K, Ahmed R, Pulendran B (2011) Systems biology of vaccination for seasonal influenza in humans. Nat Immunol 12:786-795

Nokes DJ, Okiro EA, Ngama M, Ochola R, White L, Scott PD, English M, Cane PA, Medley GF (2008) Respiratory syncytial virus infection and disease in infants and young children observed from birth in Kilifi District, Kenya. Clin Infect Dis 46:50-57

Obermoser G, Presnell S, Domico K, Xu H, Wang Y, Anguiano E, ThompsonSnipes L, Ranganathan R, Zeitner B, Bjork A, Anderson D, Speake C, Ruchaud E, Skinner J, Alsina L, Sharma M, Dutartre H, Cepika A, Israelsson E, Nguyen P, Nguyen QA, Harrod AC, Zurawski SM, Pascual V, Ueno H, Nepom GT, Quinn C, Blankenship D, Palucka K, Banchereau J, Chaussabel D (2013) Systems scale interactive exploration reveals quantitative and qualitative differences in response to influenza and pneumococcal vaccines. Immunity 38:831-844

Peiris JS, Yu WC, Leung CW, Cheung CY, Ng WF, Nicholls JM, Ng TK, Chan KH, Lai ST, Lim WL, Yuen KY, Guan Y (2004) Re-emergence of fatal human influenza A subtype H5N1 disease. Lancet 363:617-619

Peiris JS, Cheung CY, Leung CY, Nicholls JM (2009) Innate immune responses to influenza A H5N1: friend or foe? Trends Immunol 30:574-584

Pennings JL, Schuurhof A, Hodemaekers HM, Buisman A, de Rond LC, Widjojoatmodjo MN, Luytjes W, Kimpen JL, Bont L, Janssen R (2011) Systemic signature of the lung response to respiratory syncytial virus infection. PLOS One 6:e21461

Piedra PA (2003) Clinical experience with respiratory syncytial virus vaccines. Pediatr Infect Dis J 22:S94-99

Pulendran B (2009) Learning immunology from the yellow fever vaccine: innate immunity to systems vaccinology. Nat Rev Immunol 9:741-747

Pulendran B, Ahmed R (2006) Translating innate immunity into immunological memory: implications for vaccine development. Cell 124:849-863

Pulendran B, Oh JZ, Nakaya HI, Ravindran R, Kazmin DA (2013) Immunity to viruses: learning from successful human vaccines. Immunol Rev 255:243-255

Querec T, Bennouna S, Alkan S, Laouar Y, Gorden K, Flavell R, Akira S, Ahmed R, Pulendran B (2006) Yellow fever vaccine YF-17D activates multiple dendritic cell subsets via $\operatorname{TLR} 2,7,8$, and 9 to stimulate polyvalent immunity. J Exp Med 203:413-424

Querec TD, Akondy RS, Lee EK, Cao W, Nakaya HI, Teuwen D, Pirani A, Gernert K, Deng J, Marzolf B, Kennedy K, Wu H, Bennouna S, Oluoch H, Miller J, Vencio RZ, Mulligan M, Aderem A, Ahmed R, Pulendran B (2009) Systems biology approach predicts immunogenicity of the yellow fever vaccine in humans. Nat Immunol 10:116-125

Radhakrishnan A, Yeo D, Brown G, Myaing MZ, lyer LR, Fleck R, Tan BH, Aitken J, Sanmun D, Tang K, Yarwood A, Brink J, Sugrue RJ (2010) Protein analysis of purified respiratory syncytial virus particles reveals an important role for heat shock protein 90 in virus particle assembly. Mol Cell Proteomics 9:1829-1848

Rhorer J, Ambrose CS, Dickinson S, Hamilton H, Oleka NA, Malinoski FJ, Wittes J (2009) Efficacy of live attenuated influenza vaccine in children: A meta-analysis of nine randomized clinical trials. Vaccine 27:1101-1110

Roy P, Noad R (2009) Virus-like particles as a vaccine delivery system: myths and facts. Adv Exp Med Biol 655:145-158

Sanders CJ, Doherty PC, Thomas PG (2011) Respiratory epithelial cells in innate immunity to influenza virus infection. Cell Tissue Res 343:13-21
Saphire AC, Gallay PA, Bark SJ (2006) Proteomic analysis of human immunodeficiency virus using liquid chromatography/tandem mass spectrometry effectively distinguishes specific incorporated host proteins. J Proteome Res 5:530-538

Scott PD, Ochola R, Ngama M, Okiro EA, James Nokes D, Medley GF, Cane PA (2006) Molecular analysis of respiratory syncytial virus reinfections in infants from coastal Kenya. J Infect Dis 193:59-67

Segovia J, Sabbah A, Mgbemena V, Tsai SY, Chang TH, Berton MT, Morris IR, Allen IC, Ting JP, Bose S (2012) TLR2/MyD88/NF-kappaB pathway, reactive oxygen species, potassium efflux activates NLRP3/ASC inflammasome during respiratory syncytial virus infection. PLoS One 7:e29695

Shaw ML, Stone KL, Colangelo CM, Gulcicek EE, Palese P (2008) Cellular proteins in influenza virus particles. PLoS Pathog 4:e1000085

Shinya K, Gao Y, Cilloniz C, Suzuki Y, Fujie M, Deng G, Zhu Q, Fan S, Makino A, Muramoto Y, Fukuyama S, Tamura D, Noda T, Eisfeld AJ, Katze MG, Chen H, Kawaoka Y (2012) Integrated clinical, pathologic, virologic, and transcriptomic analysis of $\mathrm{H} 5 \mathrm{~N} 1$ influenza virus-induced viral pneumonia in the rhesus macaque. J Virol 86:6055-6066

Smith GE, Flyer DC, Raghunandan R, Liu Y, Wei Z, Wu Y, Kpamegan E, Courbron D, Fries LF 3rd, Glenn GM (2013) Development of influenza H7N9 virus like particle (VLP) vaccine: homologous A/Anhui/1/2013 (H7N9) protection and heterologous A/chicken/Jalisco/CPA1/2012 (H7N3) cross-protection in vaccinated mice challenged with H7N9 virus. Vaccine 31:4305-4313

Song H, Wittman V, Byers A, Tapia T, Zhou B, Warren W, Heaton P, Connolly K (2010) In vitro stimulation of human influenza-specific CD8+ T cells by dendritic cells pulsed with an influenza virus-like particle (VLP) vaccine. Vaccine 28:5524-5532

Song JM, Choi CW, Kwon SO, Compans RW, Kang SM, Kim SI (2011) Proteomic characterization of influenza H5N1 virus-like particles and their protective immunogenicity. J Proteome Res 10:3450-3459

Steinman RM (2008) Dendritic cells in vivo: a key target for a new vaccine science. Immunity 29:319-324

Tate MD, Deng YM, Jones JE, Anderson GP, Brooks AG, Reading PC (2009) Neutrophils ameliorate lung injury and the development of severe disease during influenza infection. J Immunol 183:7441-7450

Tate MD, Brooks AG, Reading PC, Mintern JD (2012) Neutrophils sustain effective CD8(+) T-cell responses in the respiratory tract following influenza infection. Immunol Cell Biol 90:197-205

Thomas PG, Dash P, Aldridge JR Jr, Ellebedy AH, Reynolds C, Funk AJ, Martin WJ, Lamkanfi M, Webby RJ, Boyd KL, Doherty PC, Kanneganti TD (2009) The intracellular sensor NLRP3 mediates key innate and healing responses to influenza $A$ virus via the regulation of caspase-1. Immunity 30:566-575

Tisoncik JR, Korth MJ, Simmons CP, Farrar J, Martin TR, Katze MG (2012) Into the eye of the cytokine storm. Microbiol Mol Biol Rev 76:16-32

To KF, Chan PK, Chan KF, Lee WK, Lam WY, Wong KF, Tang NL, Tsang DN, Sung RY, Buckley TA, Tam JS, Cheng AF (2001) Pathology of fatal human infection associated with avian influenza A H5N1 virus. J Med Virol 63:242-246

Tripp RA, Mejias A, Ramilo O (2013) Host gene expression and respiratory syncytial virus infection. Curr Top Microbiol Immunol 372:193-209

Tsang JS, Schwartzberg PL, Kotliarov Y, Biancotto A, Xie Z, Germain RN, Wang E, Olnes MJ, Narayanan M, Golding H, Moir S, Dickler HB, Perl S, Cheung F (2014) Global analyses of human immune variation reveal baseline predictors of postvaccination responses. Cell 157:499-513

Tumpey TM, Garcia-Sastre A, Taubenberger JK, Palese P, Swayne DE, Pantin-Jackwood MJ, Schultz-Cherry S, Solorzano A, Van Rooijen N, Katz JM, Basler CF (2005) Pathogenicity of influenza viruses with genes from the 1918 pandemic virus: functional roles of alveolar macrophages and neutrophils in limiting virus replication and mortality in mice. J Virol 79:14933-14944

Vester D, Rapp E, Kluge S, Genzel Y, Reichl U (2010) Virus-host cell interactions in vaccine production cell lines infected with different human influenza A virus variants: a proteomic approach. J Proteome 73:1656-1669

Vincent FB, Saulep-Easton D, Figgett WA, Fairfax KA, Mackay F (2013) The BAFF/ APRIL system: emerging functions beyond B cell biology and autoimmunity Cytokine Growth Factor Rev 24:203-215

Welliver TP, Garofalo RP, Hosakote Y, Hintz KH, Avendano L, Sanchez K, Velozo L, Jafri H, Chavez-Bueno S, Ogra PL, McKinney L, Reed JL, Welliver RC Sr (2007) Severe human lower respiratory tract illness caused by respiratory syncytial virus and influenza virus is characterized by the absence of pulmonary cytotoxic lymphocyte responses. J Infect Dis 195:1126-1136 
Wu CY, Yeh YC, Yang YC, Chou C, Liu MT, Wu HS, Chan JT, Hsiao PW (2010) Mammalian expression of virus-like particles for advanced mimicry of authentic influenza virus. PLoS One 5:e9784

Yang F, Wang F, Guo Y, Zhou Q, Wang Y, Yin Y, Sun S (2008) Enhanced capacity of antigen presentation of HBC-VLP-pulsed RAW264.7 cells revealed by proteomics analysis. J Proteome Res 7:4898-4903

Zhu FX, Chong JM, Wu L, Yuan Y (2005) Virion proteins of Kaposi's sarcoma-associated herpesvirus. J Virol 79:800-811

Submit your manuscript to a SpringerOpen ${ }^{\circ}$ journal and benefit from:

- Convenient online submission

- Rigorous peer review

- Immediate publication on acceptance

- Open access: articles freely available online

- High visibility within the field

- Retaining the copyright to your article

Submit your next manuscript at $\gg$ springeropen.com 